\title{
Influence of TAS' Characteristics on the Related Drayage Network
}

\author{
Ann-Kathrin Lange* , Kristof Ole Kühl, Anne Kathrina Schwientek, Carlos Jahn \\ Institute of Maritime Logistics, Hamburg University of Technology, \\ Am Schwarzenberg-Campus 4, 21073 Hamburg; *ann-kathrin.lange@tuhh.de
}

SNE 29(3), 2019, 137 - 140, DOI: 10.11128/sne.29.sn.10486 Received: June 15, 2019 (Selected ASIM SST Hamburg 2018 Postconf. Publ.), Accepted: July 22, 2019

SNE - Simulation Notes Europe, ARGESIM Publisher Vienna, ISSN Print 2305-9974, Online 2306-0271, www.sne-journal.org

Abstract. Truck drayage transports in the port connect container terminals with other logistics nodes as empty container depots, freight stations or customs stations. Due to the large proportion of drayage transports in the overall truck arrivals at container terminals and their relatively high costs in the maritime transport chain, drayage transports have high importance in port processes. To reduce peaks in truck arrivals, container terminals more and more often implement truck appointment systems (TAS), which require trucking companies to book specific time windows for handling prior to their transports. Besides on their impact on the container terminals, these TAS also effect the other stakeholders in the drayage net- work, which has been neglected in scientific studies so far. This study aims to analyze the effect of TAS capacity and utilization on the arrival times at other logistics nodes as well as on the number of successfully executed orders per truck.

\section{Introduction}

Containerized maritime transport grows continuously since 2010 as well as before 2009 [1]. To enable lower prices and to diminish the emissions per transported container, shipping companies are ordering larger and larger vessel sizes. In 2006, the largest ship by far was the Emma Maersk with a capacity of about 15,000 Twenty-Foot equivalent Units (TEU). In contrast, the largest ship in 2017, the OOCL Hong Kong, has a capacity of over 21,000 TEU. The growing vessel sizes pose many different challenges for the container terminals as well as for the overall port area. When considering the landside operations of a container terminal, the main challenge is the peaks in truck arrivals causing the terminal gate to have either too few personnel to prevent long queues reaching the access roads to the terminal or too much personal causing high costs for the terminal. Furthermore, the waiting trucks lead to high $\mathrm{CO}_{2}$-emissions due to their running engines. To mitigate these effects, an effective solution is to implement a truck appointment system (TAS) at the container terminal. A TAS is a vehicle booking system used to control the number of trucks arriving at the terminal at different times of the day. With this system, the trucking companies have to book specific time windows to deliver or pick up a container at the terminal. This does not only affect the container terminals and the trucking companies, but also other operative companies in the port, due to shifts in truck arrivals and higher restrictions in the dispatching process of trucking companies.

The aim of this study is to analyze the effects of varying TAS' characteristics on different operative stakeholders in the port network. To do so, many different characteristics, e.g. the length of the time window or the capacity per time window, are studied on their singular and combined impact on the arrival times at logistics nodes as well as on the amount of successfully executed orders per truck. First of all, the state of research is presented. Afterwards the simulation study and the experimental design are described. Finally, the results of the study are outlined and a conclusion is given.

\section{Port Drayage Operations}

Port drayage is defined as "truck pickup from or delivery to a seaport, with the trip origin and destination in the same urban area" ([2], [3]). Sometimes, drayage transports are also called inter-terminal trans- 
ports (ITT), with the one difference, that ITT always take place between different container handling areas in one port and does not consider other logistics nodes as freight or customs stations. The main cause for drayage transports is the necessity to transport shipment containers from one terminal to the next. On container terminals, there are mainly three types of orders: import, export and transhipment. Import container arrive at the terminals via ocean carrier and leave on barge, train or truck. Export containers arrive vice versa per barge, truck or train and leave per ocean carrier. Transhipment containers are discharged from one vessel, stored, and afterwards loaded on another vessel. As not all vessels stop at all container terminals in one port, many transhipment containers need to be trans- ported to other terminals, mainly by truck and some- times by train or barge. Furthermore, empty containers, which often have long storage times, are mainly transported to empty container depots to save storage space on seaport container terminals. Other containers are packed or unpacked in freight stations or need to be transported to customs stations. All these transports are called drayage transports if the origin and destination are in the same area. Due to their large proportion of truck arrivals at container terminals and their relatively high costs, they present an important part of the overall maritime supply chain (inter alia [4], [5]).

\section{State of Research}

The first TAS was introduced in the ports of Los Angeles and Long Beach in 2002 in response to California Assembly Bill (AB) 2650. The evaluation of the program was mixed, due to high entry barriers for the truck drivers, as varying systems for registration and a generally high effort for the overall process, and therefore due to a low participation [6]. Main reason for the intro- duction of a TAS is the need to reduce $\mathrm{CO}_{2}$-emissions. Other goals are to reduce truck waiting times at the gates or to improve the terminal processes. Therefore, the TAS as well as other approaches, as webcams at the terminal gates to provide information about the current congestion (e.g. [3]) or to promote transports outside peak times by introducing varying tolls in the port (e.g. [7]), have been studied increasingly. Today, several successful TAS are running in different parts of the world, e.g. Vancouver,
Sydney and Southampton, but the development goes on to improve these systems or to find better alternatives (inter alia [8], [9]).

Scientific studies focus mainly on the effects of TAS on container terminal productivity (e.g. [10], [11]). Other publications also consider the possible benefits and challenges for trucking companies (e.g. [12], [13]). To the authors' knowledge, other actors, as empty container depots, freight stations or customs station, are never considered. For a comprehensive overview about literature on port drayage transports and TAS be referred to Lange et al. 2017 [14].

\section{Simulation Study}

As described above, the focus of this study is on port drayage transports. Therefore, only transports in the port area and between the relevant operative stakeholders are considered. For the simulation study, the program Tecnomatix Plant Simulation 13 is used because it is widely recognized in industry and this research area. The simulation model is generated based on operative data of different stakeholders in the port of Hamburg, especially transport data from trucking companies and process durations from various logistics nodes. Asimulation run covers one workday from 0 to 24 o'clock. Every simulation experiment is repeated 20 times.

For the simulation model, a flexible list of orders for one considered trucking company is generated. In this list, the source and the drain of every order is noted. In the next step, time windows are booked for all orders with either source, drain or both at container terminals. For all time windows specific probabilities for a successful booking are considered, based on the assumed utilization of this time window by other trucking companies. The order list is imported in the simulation model. There, all relevant stakeholders are displayed. In every simulation run, one trucking company, four container terminals, six empty container depots, six freight stations and five other logistics nodes are considered. The driving distances between the individual stakeholders are represented by a distance relation matrix, considering the driving durations at different times of the day due to traffic. The durations are determined by using a Google Maps API for the relevant routes between logistics nodes in the port of Hamburg. Similarly, the handling times at the various 
logistic nodes differ based on the time of the day. At the beginning of every simulation run, the transport orders for the trucking company are checked and each truck is assigned one order. When the first order is completed, a next order is chosen for the truck. When a truck arrives too late at its destination, the order is cancelled and a new order is assigned.

\section{Experimental Design}

The parameters for the simulation experiments were determined in interviews with different stakeholders in the drayage network in the port of Hamburg. In addition, relevant scientific publications were analyzed. In the simulation experiments, a medium-sized trucking company with 25 trucks and 375 possible orders per day is considered. $50 \%$ of the transports are executed between container terminals and $8.3 \%$ each be- tween container terminals and empty container depots, packing stations and the remaining logistics nodes, vice versa. Transports only between empty container depots, freight stations and other logistics nodes are not considered. Furthermore, the working times of all logistics nodes, except container terminals, which always have three shifts, are limited. Therefore, they restrict the productivity of drayage transports as well as the efficiency of TAS at container terminals. As for TAS' characteristics, the capacity of the time windows in the different shifts (based on current demand, lightly smoothed and heavily smoothed) is varied. In the first shift there are either 40,60 or 80 slots in total. In the second shift there are 120,100 or 80 and in the third are always 80 slots. Furthermore, the utilization of the time windows by other trucking companies $(80 \%, 85 \%$ and $90 \%)$ is varied for the peak times between 9 am and $6 \mathrm{pm}$. The peak time has been set based on data provided by logistics nodes in the port of Hamburg. The overview of all experiments and their parameters is shown in Table 1.

\begin{tabular}{llll}
\hline & \multicolumn{3}{c}{ Utilization } \\
\cline { 2 - 4 } Capacity & $\mathbf{8 0} \%$ & $\mathbf{8 5} \%$ & $\mathbf{9 0 \%}$ \\
\hline Realistic & Exp. 1 & Exp. 4 & Exp. 7 \\
\hline Lightly smoothed & Exp. 2 & Exp. 5 & Exp. 8 \\
\hline Heavily smoothed & Exp. 3 & Exp. 6 & Exp. 9 \\
\hline
\end{tabular}

Table 1: Plan of experiments.

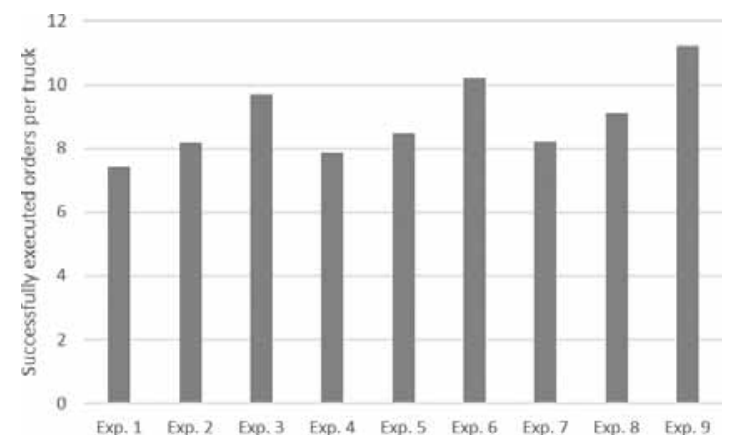

Figure 1: Successfully executed orders per truck and day.

\section{Simulation Results}

The results show a high impact of the two selected TAS' characteristics on the operative stakeholders. In Figure 1 , the amount of successfully executed orders is shown. It is surprising to see that the heavily smoothed TAS capacity leads to a better solution as well as the high capacity utilization by other trucking companies. This effect is very likely caused by the structure of transport orders generated. As a high amount of transports is executed between container terminals and only a lesser amount between container terminals and other logistics nodes, vice versa, the trucks are able to pick up and deliver containers 24/7. In the simulation model, the time windows at peak times have a higher priority and are therefore, chosen first. If no time windows in peak hours are left, the time windows in off-peak hours are booked. This leads to shorter waiting times at the terminals due to the lower assumed handling times as well as to less congestion in the port and thereby, to lower trans- port times. Furthermore, transports in the peak times tend to be more risky due to a higher variance in trans- port and handling times. Therefore, more transports in peak hours need to be cancelled due to predicted late arrivals at their destination. This reduces the productivity of the trucking companies considerably.

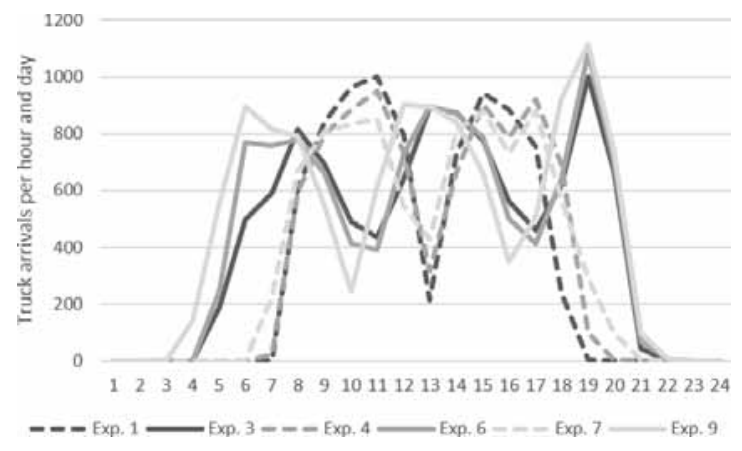

Figure 2: Truck arrival times at all types of logistics nodes for Exp. 1,3,4,6,7 and 9. 
A similar effect can be seen in Figure 2. There, the arrivals at logistics nodes are spread out in a wider time range for Exp. 3, 6 and 9 compared to Exp. 1, 4 and 7. Considering the lower transport and handling times at the off-peak hours, this leads to a higher number of executed transports and therefore, to a higher productivity for the trucking companies. The transports executed in the off-peak hours are mainly interterminal transports, as the other logistics nodes tend to have limited working hours. This fact can also be seen in Figure 3, where the truck arrival times at container terminals and other logistics nodes are shown exemplarily for Exp. 1 and 9. It is evident that the inter-terminal transports in Exp. 9 are further shifted to off-peak hours. A high percent- age of the transports in peak hours is executed between container terminals and other logistics nodes.

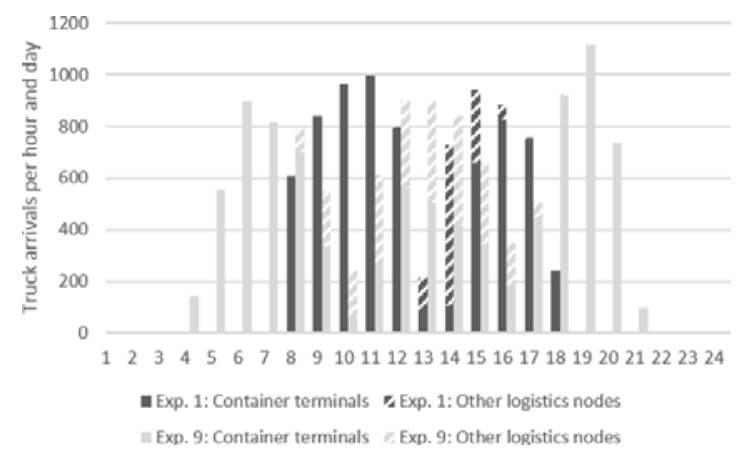

Figure 3: Detailed truck arrival times for Exp. 1 and 9.

\section{Conclusion and Outlook}

In conclusion, a TAS offers chances for trucking companies as well as for logistics nodes. Especially, if a trucking company executes many inter-terminal transports it is flexible enough to adapt to a TAS and seize the opportunities. It is expected that the results would change considerably if a higher amount of non-interterminal transports is assumed. In this case, the restrictions imposed by TAS and limited opening hours of other logistics nodes would very likely reduce trucking companies' productivity when the available capacity is limited. In future, more TAS' characteristics should be analyzed on their impact on the different stakeholders in drayage networks. Furthermore, a broader variance in booking strategies for the trucking companies as well as operations at logistics nodes should be considered.

\section{References}

[1] United Nations Conference on Trade and Development. Review of maritime transport 2017. New York, Geneva: United Nations; 2017
[2] Hartmann S. Generating scenarios for simulation and optimization of container terminal logistics. OR Spectrum. 2004; 26, 171-192.

[3] Huynh N, Harder F, Smith D, Sharif O, Pham Q. Truck Delays at Seaports. Transportation Research Record: Journal of the Transportation Research Board. 2011; 2222, 54-62.

[4] Harrison R, Hutson N, West J, Wilke J. Characteristics of Drayage Operations at the Port of Houston, Texas. Transportation Research Record: Journal of the Transportation Research Board. 2007;2033: 31-37.

[5] Shiri S, Huynh N. Optimization of drayage operations with time-window constraints. International Journal of Production Economics. 2016; 176: 7-20.

[6] Giuliano G, O’Brien T. Reducing port-related truck emissions. The terminal gate appointment system at the Ports of Los Angeles and Long Beach. Transportation Research Part D: Transport and Environment. 2007; 12: 460-473.

[7] Bentolila DJ, Ziedenveber RK, Hayuth Y,Notteboom T. Off-peak truck deliveries at container terminals: the "Good Night" program in Israel. Maritime Business Review. 2016; 1/1(1):2-20.

[8] Davies P, Kieran M.E. Port Congestion andDrayage Efficiency. METRANS International Urban Freight Conference. 2015 Oct; Long Beach, USA.

[9] Huynh N, Smith D, Harder F. Truck Appointment Systems. Transportation Research Record: Journal of the Transportation Research Board. 2016; 2548: 1-9.

[10] Chen G, Govindan K, Yang Z-Z, Choi T-M, Jiang L. Terminal appointment system design by nonstationary $\mathrm{M}(\mathrm{t}) / \mathrm{Ek} / \mathrm{c}(\mathrm{t})$ queueing model and genetic algorithm. International Journal of Production Economics. 2013; 146: 694-703.

[11] Zhao W, Goodchild AV.The impact of truck arrival information on container terminal rehandling. Transportation Research Part E: Logistics and Transportation Review. 2010; 46: 327-343.

[12] Heilig L, Lalla-Ruiz E, Voß S. port-IO. An integrative mobile cloud platform for real-time inter-terminal truck routing optimization. Flex Serv Manuf J. 2017; 29: 504-534.

[13] Namboothiri R, Erera AL. Planning local container drayage operations given a port access appointment system. Transportation Research Part E: Logistics and Transportation Review. 2008; 44: 185-202.

[14] Lange A-K, Schwientek A, Jahn C. Reducing truck congestion at ports - classification and trends. In: Jahn C, Kersten W, Ringle C M, editors. Digitalization in maritime and sustainable logistics. City logistics, port logistics and sustainable supply chain management in the digital age. Hamburg International Conference of Logistics. 2017 Sep; Hamburg, Germany:epubli. 37-58. 